\title{
Turismo no meio urbano e a segregação socioespacial: revisitando problemáticas
}

\section{Urban tourism and socio-spatial segregation: revisited problems}

\author{
Luiz Fernando Roscoche (ROSCOCHE, L. F.)
}

RESUMO - O presente trabalho tem por objetivo realizar uma revisão bibliográfica sobre a temática da ocorrência do turismo no meio urbano, levantando as principais problemáticas estudadas por diversos autores ao mesmo tempo em que se busca apontar algumas lacunas teóricas que estariam sendo negligenciadas. Dentro da temática do turismo no meio urbano, discute-se ao final do trabalho a da segregação socioespacial gerada pelas atividades turísticas em espaços urbanos.

Palavras-chave: Turismo urbano; Segregação socioespacial; Urbano.

ABSTRACT - The objective of this paper was to conduct a literature review on the subject of urban tourism, raising the main issues studied by the authors at the same time that it seeks to identify some theoretical gaps that were being neglected. Within the theme of urban tourism, discusses the end of the work the problem of spatial segregation in urban tourism.

Key words: Urban tourism; Sociospatial segregation; Urban.

\footnotetext{
* Formação: Graduação em Geografia (Licenciatura) pela Universidade Estadual de Ponta Grossa (UEPG), Mestrado em Turismo pela Universidade de Caxias do Sul (UCS), Doutorando do Programa de Pós-Graduação em Geografia da Universidade Federal de Goiás (UFG). Atividade profissional: Professor efetivo da Universidade Federal do Pará (UFPA) - Faculdade de Educação (Campus de Bragança). Endereço físico para correspondência: Rua Leandro Ribeiro s/n. CEP 68.370-000 - Bragança - Pará (Brasil). E-mail: luizfrrs@ hotmail.com
} 


\section{INTRODUÇÃO}

Constata-se que grande parte da atividade turística acontece em grandes centros urbanos de todo o mundo. Segundo o Ministério do Turismo no Brasil (2010), citando dados da OMT (Organização Mundial de Turismo), os destinos mais visitados no mundo estão na Europa e o patrimônio cultural é uma das principais motivações para o turismo (FERREIRA; AGUIAR; PINTO, 2012).

Como bem lembra Yázigi (2003), o urbano realmente não é o único tipo de território onde o turismo acontece, mas certamente é um dos lugares mais importantes considerando o fato de que, é o lugar por excelência do encontro social e cultural. Prossegue afirmando que "mesmo quando o destino turístico ocorre em meio natural, poucos são os casos em que a cidade não se interpõe como escala conveniente ou obrigatória" (YAZIGI, 2003, p. 71). Fica evidente que existe uma interdependência entre esses dois territórios e que mesmo quando a principal motivação da atração é ligada a atrativos naturais as cidades possuem um papel importante no fornecimento de grande parte da infraestrutura turística necessária.

As cidades recebem um considerável volume de tráfego, gerado pelas várias funções que exercem, sejam elas administrativas, comerciais e/ou industriais, que atraem grande número de grupos de visitantes. (PEARCE, 2003). Muitos centros urbanos possuem funções varejistas e de entretenimento e refletem funções contemporâneas. Segundo Harvey (apud URRY, 2001 p. 61) ${ }^{1}$, a cidade precisa ser um lugar "inovador, criativo e seguro onde se possa viver, divertir-se e consumir". O novo e o velho interagem num movimento constante, pois nesses centros existe a concentração de edifícios e monumentos históricos coexistindo com inúmeras edificações e tecnologias pós-modernas. (PEARCE, 2003).

\footnotetext{
${ }^{1}$ HARVEY, D. Flexibe accumulation through urbanism: reflections on 'postmodernism' in the American city. Antipode. v. 19, p. 260-286, 1987.
} 


\section{AS PROBLEMÁTICAS DE INVESTIGAÇÃO DO TURISMO EM ESPAÇOS URBANOS}

Se, por um lado, é reconhecida a importância do turismo nos espaços urbanos, por outro, ainda existe uma dificuldade em se definir o que é urbano em contraposição ao que é rural (especialmente em territórios com forte presença da ciência, técnica e informação) (RODRIGUES, 1999). Ainda segundo a mesma autora, no que se refere ao turismo essa dificuldade seria ainda maior A situação se agrava ainda mais quando se verifica a dificuldade na abordagem da urbanização brasileira no momento atual, que segundo Rodrigues (1999), estaria marcada pela velocidade e pela técnica, e pela fusão das categorias de espaço e tempo.

Mais do que reconhecer a importância e relação recíproca entre o urbano e o turismo, julga-se ser necessário identificar os principais entraves para o estudo desse fenômeno no ambiente urbano, mesmo porque estes são complexos e que muitas vezes são analisados de maneira incompleta.

Tyler, Guerrier (2001, p. 309), consideram que o turismo no meio urbano deve transcender à simples questão da oferta e da procura e inserir-se como um mecanismo de gestão e modificação das cidades e de suas funções, fazendo com que promova uma resposta social e política para a sociedade pós-moderna.

Autores como Pearce (2003) e Tyler, Guerrier (2001) ilustram que continua havendo pouco estudo do em áreas urbanas, pois, como complementa Yázigi (2003, p. 232), "enquanto que o meio natural conta com um exército de defensores, as cidades padecem de fraca legião urbana". Pearce (1999) alerta que, assim como em muitas outras áreas, o estudo dos espaços turísticos urbanos não estaria sustentado por uma base teórica extensa. A maior parte da produção acadêmica referente ao meio urbano é fruto de um contínuo interesse demonstrado entre a atividade turística e o (re)desenvolvimento ou a conservação dos centros urbanos, principalmente dos centros históricos como é demonstrado nas obras de Orbasli (2000); Asworth e Tunbridge (2000), ou ainda enfocando questões sobre oferta e demanda (TYLER, GUERRIER, 2001).

Segundo Pearce (2001), ao se verificar as publicações sobre a atividade turística no meio urbano, verificam-se temas relacionados com oferta, desenvolvimento, 
marketing, planejamento, organização, operações e avaliação dos efeitos. Ainda ressalta que é possível se utilizar a questão espacial para ordenar os temas turísticos (oferta, desenvolvimento, dentre outros) em uma variedade de contextos, dependendo do nível de cada problema.

Como lembram Asworth e Tunbridge (2000), é difícil isolar a atividade turística das demais atividades desenvolvidas nos centros urbanos assim como distinguir produtos e serviços utilizados por turistas e por outros usuários. A dificuldade seria extrair a atividade turística no meio urbano de seu próprio contexto. Essas dificuldades intrínsecas podem ajudar a explicar a omissão no estudo da atividade turística no meio urbano.

Page $^{2}$ (apud TYLER, GUERRIER, 2001) considera que existem lacunas no que se refere ao entendimento do fenômeno turístico e de seu respectivo funcionamento, especialmente em áreas urbanas. Segundo Pearce (2001), o atraso da investigação sobre o fenômeno do turismo no meio urbano se deu em razão de sua complexidade, representando assim um grande desafio para muitos pesquisadores no momento de registrar movimentos e observar comportamentos. Porém, Pearce, (2001) menciona que o uso de técnicas inovadoras pode proporcionar subsídios para uma melhor análise do fenômeno.

Analisando assim partes do sistema turístico, nos centros urbanos, de maneira separada, reduzem-se não só as perspectivas de análise do fenômeno, tratando-o de maneira reducionista e equivocada, como também poder-se-ia estar perpetuando uma imagem distorcida e sem representatividade do fenômeno turístico perante a sociedade. Ao se definir claramente o objeto de análise, deslumbrando a totalidade do fenômeno turístico nos centros urbanos, seria possível desenvolver ações de forma mais apropriada, assim como haveria maior discussão desse processo com a sociedade.

Pearce (2003) aponta outro problema que prejudicaria a investigação do fenômeno turístico no meio urbano: a "relativa negligência do turismo nas áreas urbanas pode ser atribuída, em parte, às diferenças no papel desempenhado por essas áreas nas indústrias turísticas nacionais e à relativa importância do turismo nas cidades".

Segundo esse autor (2001), os estudos de turismo no meio urbano estão estreitamente contextualizados em processos mais amplos, tais como reestruturação

\footnotetext{
${ }^{2}$ PAGE, S. Urban Tourism. Londres: Routledge, 1995.
} 
econômica, globalização e localização. A estrutura das atrações turísticas urbanas, além de outras instalações, pode ser considerada como uma rede de nódulos, ou de concentrações de nódulos, e de estradas que as ligam entre si. Assim, expõe que, se por um lado pouco se conhece sobre os movimentos intraurbanos dos turistas, por outro lado é possível reconhecer seus itinerários e caminhos. (PEARCE, 2003).

O autor segue ainda afirmando que:

O turismo urbano tem sido utilizado por parte de um bom número de autores para explorar processos mais amplos, que se têm examinado desde distintas perspectivas teóricas e que colocam como manifesto a necessidade de situar as cidades individuais em um contexto geográfico, econômico e político muito mais amplo. (PEARCE, 2001, p. 355).

Pearce $(1985,2003,2001)$, na tentativa de uma maior sistematização do estudo do turismo no meio urbano, busca enfocar em suas obras a organização do território e procura propor um método de análise para o turismo no meio urbano, pois, segundo este: "a complexidade, fragmentação e falta de coerência implica um esquema de estudo claro e analítico que proporcione uma perspectiva mais sistemática sobre os temas próprios do turismo urbano". (PEARCE, 2001, p. 342).

Segundo esse autor, existe a necessidade de uma análise mais integradora que examine as conexões existentes entre os temas que compõem o esquema de apreciação do desenvolvimento turístico em seus mais diversos níveis e contextos. (PEARCE, 2001).

E é nesta busca, de um maior detalhamento e compreensão das conexões e dos processos da atividade turística que Pearce (1999), critica a forma como muitos estudos científicos que enfocam o turismo no meio urbano são realizados, analisando somente a morfologia dos processos e a distribuição dos fixos e dos fluxos ${ }^{3}$ do turismo, alienandose então de uma análise mais profunda da estrutura e dos processos, principalmente em microescala.

\footnotetext{
${ }^{3} \mathrm{Na}$ visão de Santos (1996), o espaço pode ser definido como um conjunto indissociável de sistema de objetos e de sistema de ações, ou em outras palavras, fixos e fluxos. Segundo o autor os sistemas de objetos condicionam até certo ponto o sistema de ações e vice-versa. Podem ser considerados como exemplo de fixos as estradas, as hidrelétricas, já os fluxos seriam os automóveis que transportam mercadorias e pessoas ou ainda a energia que é transportada pelo sistema de abastecimento de energia elétrica.
} 
Tyler, Guerrier (2001), também criticam a maneira como ocorrem os estudos sobre o turismo no meio urbano, pois, segundo eles, deveriam transcender à simples questão da oferta e procura e inserir-se como um mecanismo de gestão e modificação das cidades e de suas funções, fazendo com que o turismo no meio urbano promova uma resposta social e política para a sociedade pós-moderna.

Deve-se partir do princípio de que o turismo é apenas uma das atividades desenvolvidas nos centros urbanos, mas ainda assim é um dos processos que contribui para a configuração dos seus territórios.

\section{CIDADES TURÍSTICAS E URBANIZAÇÃO TURÍSTICA}

Para um melhor entendimento das relações entre o turismo e o meio urbano, é imprescindível introduzir-se alguns conceitos básicos e até mesmo questionamentos em torno da natureza das características que abarcam o processo de urbanização turística e até mesmo das cidades turísticas. Cabe questionar se efetivamente existiria ou seria correto utilizarem-se as denominações "urbanização turística" ou ainda "cidades turísticas". Porém, indiferentemente de tal questionamento é possível verificar uma lógica diferenciada sobre as questões urbanas nas cidades onde o turismo é uma das atividades principais.

Segundo Asworth e Tunbridge (2000), as cidades são importantes para o turismo, assim como o turismo é importante para as cidades, embora possa haver uma afirmação contrária de que, muitas vezes, o turismo não é importante para as cidades, haja vista que o turismo pode não ter para elas uma relevância significativa em termos econômicos, culturais e ambientais, podendo outras atividades exercer o papel principal.

Umas das grandes dificuldades, no entanto, reside em definir as "cidades turísticas". Segundo Silva (2004, p. 87): “a caracterização de cidade ou município turístico, ainda sem definição pela legislação até 2003, torna difícil uma classificação mais precisa e mesmo a compilação de estatísticas sobre o fluxo de turistas no Brasil".

Silva (2004) considera turísticos os municípios ou distritos municipais cuja economia local esteja baseada essencialmente no turismo, estabelecendo assim uma diferenciação entre lugar ou localidade turística, que representariam para qualquer 
espaço onde se desenvolve a atividade turística. A autora fornece um exemplo da forma equivocada como um programa governamental brasileiro [O PNMT - Programa Nacional de Municipalização do Turismo] adotou as categorias Municípios Turísticos (MT) e Municípios com Potencial Turístico (MPT).

Uma das poucas definições dessa nova concepção de cidade, chamada de “cidade turística", é fornecida por Knafou (apud SILVEIRA, 1998, p. 63) ${ }^{4}$ :

[...] a cidade turística é uma aglomeração urbana onde o turismo é considerado uma atividade importante para a economia local, e pode se apresentar em termos espaciais de duas formas: uma delas é multiplicidade de sítios integrados ao tecido urbano onde a apropriação por parte do turismo de algumas zonas de uso coletivo como áreas verdes e as áreas de lazer das cidades; a outra forma é a estação turística que se define pela primazia do turismo em relação às demais atividades, isto é, o turismo produziu aquele lugar e constitui a atividade econômica predominante.

Nessa definição de cidade turística, pode-se afirmar que fica evidente a preocupação com a questão econômica e espacial, esquecendo-se dos outros aspectos que envolvem a atividade turística. No entanto, ao se considerar essa definição de "cidade turística", torna-se necessário o questionamento se existiriam realmente cidades turísticas ou espaços turísticos; afinal, o turismo não acontece em todo o espaço de forma homogênea.

Luchiari (2000) considera que uma das diferenças entre cidades industriais e cidades turísticas é que estas últimas representariam uma nova forma de urbanização, ou seja, elas não seriam concebidas para a produção (como o foram as cidades industriais), mas para o consumo de bens, serviços e paisagens. Segundo ela, "no processo de urbanização turística, o consumo tem mais visibilidade que a produção, o que não significa que a produção perca sua importância, mas que o consumo passa a ser mais constitutivo das paisagens das cidades.” (p. 124).

Porém, existem algumas cidades com as características elencadas pela autora, mas que não são necessariamente turísticas. Assim, a estrutura das cidades turísticas parece estar mais voltada aos fluxos do que aos fixos.

Fainstein e Judd (1999), ao diferenciarem também as cidades turísticas das cidades industriais, consideram que o turismo exerce impactos significativos sobre as

\footnotetext{
${ }^{4}$ KNAFOU, R. Turismo e Território: por uma abordagem científica do turismo. In: RODRIGUES, A. A. B. Turismo e geografia: reflexões teóricas e enfoques regionais. São Paulo: Ed. HUCITEC, 1996. p. 6274.
} 
formas urbanas, pois a organização dos espaços dessas cidades difere das industriais, que se especializaram historicamente na produção, distribuição e no consumo de bens. $\mathrm{Na}$ área central dessas cidades, segundo as autoras, predominam as instalações comerciais de varejo e instalações de entretenimento, em lugar de escritórios administrativos.

Segundo Silva (2004, p. 37), o espaço urbano destinado ao turismo deveria:

[...] corresponder à expectativa de um consumo da natureza pelo trabalhador. Assim, o espaço de trabalho e de moradia seria um espaço primordialmente de produção e, nos espaços de lazer, há uma ênfase no consumo, sejam de bens produzidos pelo trabalho, seja o próprio espaço construído e herdado, seja a natureza. No lugar turístico, as edificações, as ruas, as praças, os jardins, o sol, a montanha, o mar, o clima, quase tudo enfim pode ser de interesse do turista e objeto de consumo.

Para Luchiari (2000), a forma espacial como foram concebidas as cidades, no processo de revolução industrial, causou uma segregação espacial, separando assim o trabalho, o lazer e a moradia em formas e funções isoladas, articuladas, segundo ela, por frias vias de acesso, restritas aos automóveis.

Segundo Krippendorf (2000), as cidades sucumbiram às exigências da produção industrial, havendo portanto, um processo de adaptação das mesmas às necessidades da economia. Segundo o autor, houve a adoção, a partir da década de 30, de uma visão de que a chave do planejamento das cidades centrava-se em quatro funções: morar, trabalhar, descontrair-se e deslocar-se. Ainda segundo o mesmo autor, na década de 80 , verificou-se uma maior preocupação com muitos aspectos, menos o do humano.

Não se pode negar o fato da cidade turística ser em parte concebida por exigências externas, de amplitude mundial, regional e até mesmo do próprio mercado capitalista, porém, diferentemente das cidades industriais na cidade turística se busca a valorização de uma população externa (turista) ou da população interna (população local).

Autores, como Luchiari (2000), Krippendorf (2000) e Mascarenhas (2004) corroboram que o princípio da urbanização turística difere do processo de urbanização convencional (calcado no modelo industrial), por priorizar o consumo em detrimento da produção. 
Mascarenhas (2004) afirma que existem algumas características fundamentais no processo de urbanização turística, são elas: o consumo prevalecendo sobre a produção, consumo este que se realiza principalmente por sujeitos externos; altas taxas de crescimento demográfico; fluxos migratórios na busca por empregos; empregos de baixa remuneração, baixo índice de sindicalização; contraste entre tipos de habitação extremamente precários e de consumo supérfluos em zonas turísticas.

Luchiari (2000) considera que, mediante o processo de urbanização turística, é possível haver um crescimento acelerado da população e da força de trabalho, intensificado mais propriamente pelos fluxos migratórios que ocupam principalmente os setores de serviços e a construção civil, seja para a infraestrutura turística, seja para a infraestrutura urbana. $\mathrm{O}$ grande problema é que esse grande volume de pessoas acaba por constituir residência fixa no local, aumentando assim o número de pessoas que vivem em más condições de moradia e diminuindo a renda dos moradores locais. Segundo a autora, a elevação do custo de vida para a população local, o qual é geralmente mais elevado nos momentos da alta temporada.

Como bem lembra Luchiari (2000), a urbanização turística coloca as cidades no mercado das paisagens naturais e artificiais. Algumas cidades, segundo ela, podem até mesmo chegar a redefinir sua vida econômica em função do desenvolvimento turístico, embora este possa redefinir mais do que simplesmente a vida econômica do município. Isto porque, como bem expõe Neverovsky (2004), as mudanças no modo de produção modificam as relações econômicas, sociais e também o espaço onde essas relações se processam. As cidades, nesse sentido, poderiam reorganizar-se para produzir paisagens atrativas ao "consumo" e ao lazer.

Silva (2004, p. 27) afirma que as paisagens turísticas são:

[...] intencionalmente construídas no território, não apenas pela apropriação visual de panoramas, mas também pela reprodução de padrões de beleza e qualidade culturalmente estabelecidos, frequentemente, versões de uma realidade idealizada. Mesmo o que se denomina "paisagem natural" pode ser considerado um objeto cultural, pois é produto de um conjunto de imagens idealizadas que o homem tem do território e que também serve de referência para os assentamentos humanos. 
A autora ao considerar a "paisagem natural" como um elemento cultural, pois, sendo este elemento apropriado e possuindo uma utilidade, torna-se um elemento cultural e não apenas natural.

Os gestores das atividades do turismo ao se apropriarem do espaço urbano, desencadeiam uma ação dialética sobre este, destruindo e recriando territorialidades. Segundo Silva (2004), a produção do espaço turístico é marcada por outra contradição, ou seja, a contradição entre fantasia e realidade.

Assim como todo processo de apropriação espacial, as atividades vinculadas ao turismo podem gerar algumas contradições, sendo que a mais contundente delas é a segregação socioespacial. A segregação desencadeada pela apropriação do território pela atividade turística nos centros urbanos foi amplamente registrada por pesquisadores (JURDAO ARRONES, 1992; GARRIDO TORRES, 1992; MASCARENHAS, 2004; RODRIGUES, 1996 e outros).

Uma das obras de maior destaque nesse sentido é o livro organizado por Jurdao Jurdao Arrones (1992) - Los mitos del turismo, que oferece destaque ao modo como a atividade vem expropriando e segregando o espaço e a população onde ocorre, ocasionando com isso um processo de especulação imobiliária e de modificação dos modos de produção do local e dos padrões culturais. Os autores da obra analisam o esgotamento e a crise do modelo turístico espanhol que aconteceu devido a muitos fatores, como a perda de seus recursos turísticos, falta de administração, infraestrutura ruim, o excesso de oferta, e até mesmo "lavagem de dinheiro", devido às atividades de construção civil.

Os especuladores imobiliários (no caso espanhol) (REBOLLO, 1992) teriam deixado para trás um rastro de degradação financeira, ecológica e social e continuam seu ciclo procurando novos lugares, desencadeando um círculo vicioso que agrava cada vez mais os problemas locais. A obra analisa ainda a transição do modelo turístico espanhol litorâneo para um turismo ligado à natureza e ao "verde", realizando severa crítica ao turismo rural e ressaltando os impactos, principalmente ambientais, desse tipo de turismo.

Na mesma obra um artigo escrito por Garrido Torres (1992, p. 89-115) trata sobre as Ilhas Baleares, um paraíso que pouco a pouco foi se tornando através da especulação imobiliária e da venda do território, em um "inferno", trazendo inúmeros 
impactos como a modificação da estrutura social e produtiva do lugar, além de intenso processo de urbanização. Comenta que em cada ilha houve uma repercussão diferente, seja nos aspectos econômicos, sociais, espaciais ou em outros. O autor ressalta que, depois da crise de 1973, existia uma carência de infraestrutura, uma vez que se resolviam as coisas de maneira improvisada e sem planejar: um caos provocado por um urbanismo desenfreado, desencadeado pela lógica unilateral do capital.

Ressalta ainda os conflitos pelo uso do solo e a expropriação do território e da cultura do povo local, além de problemas com falta de água provocada pela construção incessante de campos de golfe, além da perda de poder e autonomia do governo local, uma vez que a venda do território ocorria de maneira desmedida.

Nesses exemplos aqui expostos, considera-se ficar evidente que a atividade turística é utilizada por agentes do capital na busca pelo lucro. Que tal processo é caracterizado por grandes assimetrias e contradições, sendo a segregação sociespacial uma das interfaces do problema. Bem como, o caráter segregador do modelo capitalista. Modelo este onde a atividade turística se insere.

Dessa forma, para fins deste estudo, tornou-se necessário compreender o processo de segregação socioespacial desencadeado pelo capital, que por sua vez se reflete da atividade turística. Como bem defende Mascarenhas (2004), "as novas cidades turísticas tendem acentuar a problemática capitalista da segregação sócioespacial".

\section{TURISMO E SEGREGAÇÃO SOCIOESPACIAL}

Segundo Villaça (2001, p. 142), a segregação seria "um processo segundo o qual, diferentes classes e camadas sociais tendem a se concentrar cada vez mais em diferentes regiões gerais e conjuntos de bairros da metrópole”.

Lojkine $^{5}$ (1981 apud Villaça 2001, p. 143) considera que a segregação é uma manifestação da renda fundiária urbana, um fenômeno "produzido pelos mecanismos de formação dos preços do solo, estes por sua vez, determinados pela nova divisão social e espacial do trabalho". Esse mesmo autor distingue três tipos de segregação a oposição

\footnotetext{
${ }^{5}$ LOJKINE, J. O Estado capitalista e a questão urbana. Martins Fontes, 1981.
} 
entre centro e periferia; zonas de moradia popular e zonas privilegiadas, e zonas especializadas (regiões onde há o predomínio de uma atividade específica, como zonas industriais, de escritórios e outros).

Para Melgaco et al. (2002, p. 1), a segregação, de modo amplo, pode ser considerada como a separação forçada ou institucionalizada de uma discriminação, como por exemplo um tratamento desigual de grupos, seja por motivo religioso, social, sexual ou outro.

Villaça (2001) cita outros autores que subdividem a segregação segundo duas formas, ou seja, a voluntária (o próprio indivíduo por sua vontade procura áreas que se enquadrem no seu interesse) e a involuntária (o indivíduo é coagido ou obrigado a sair de uma área e/ou procurar outra área para morar ou exercer qualquer outra atividade). Essa forma seria para esse autor uma luta de classes, caracterizando-se como um processo dialético, uma vez que o processo de segregação de uns, provocaria (ao mesmo tempo e pelo mesmo processo) a de outros.

Yázigi (2003) considera que a autossegregação das cidades, devido aos núcleos de condomínios fechados, centros comerciais, centros culturais, centros burocráticos, clubes sociais e desportivos e outros, surgem como uma resposta dos habitantes urbanos frente à incapacidade administrativa e policial das cidades.

Segundo Fainstein (1999), o turismo exerce impactos significativos sobre as formas urbanas, pois a organização dos espaços das cidades turísticas difere daquela das cidades industriais, que se especializaram historicamente na produção, distribuição e consumo de bens. O centro dessas cidades, segundo a autora, tende a ser dominado por instalações comerciais de varejo e instalações de entretenimento, em lugar de escritórios administrativos.

Hall (2001) ao retratar o estudo de caso de Darling Harbour (Austrália), afirma que a região central da cidade tornou-se um espaço de consumo conspícuo, onde a celebração dos produtos se sobrepõe aos valores cívicos.

Fainstein (1999), por outro lado, ressalta que o centro dessas cidades são destinos que recebem visitas abundantes e não comportam edificações residenciais, que acabam por excluir os residentes proprietários do centro. Registre-se aqui que esse processo não ocorre apenas com o desenvolvimento turístico, mas que é uma tendência do desenvolvimento urbano de modo geral. 
Smith $^{6}$ apud Crispim (1998, p. 394), reitera que o espaço cria desigualdade, pois segundo ela a localização de cada serviço favorece ou desfavorece as pessoas segundo sua distância em relação a ele, redistribuindo benefícios e malefícios. Considera-se que a afirmação de Smith, na verdade possui um pequeno equívoco, na medida em que o espaço não cria desigualdades por si mesmo, mas pelas ações empreendidas pelos sujeitos, que podem ou não se materializar no espaço.

Segundo Melgaco et al. (2002, p. 2), é através da segregação que a elite domina o espaço urbano, por meio de um processo de produção e consumo do espaço segundo seus interesses, havendo assim um processo de apropriação diferenciada do espaço urbano. Essa produção e o consumo do espaço urbano pelas classes dominantes, podem ocorrer, segundo esse autor, pela ação direta da classe dominante, pelo mercado imobiliário ou pela ação indireta, ou ainda através de relações nas quais, o Estado favorece a localização de infraestrutura urbana, dos mecanismos legislativos de uso e ocupação do solo, e entre outros.

O posicionamento de Melgaco et al. (2002, p. 2), é semelhante ao de Corrêa (2000, p. 26-27), que considera que a segregação espacial pode se dar, em muitos casos, na figura do Estado que, ao planejar ou alocar de maneira diferenciada os equipamentos de consumo coletivo, interfere na segregação residencial. A maneira como se distribuem quantitativa e qualitativamente os equipamentos públicos de uso coletivo pode levar a uma intensificação das desigualdades sociais. Castells ${ }^{7}$ (1978, apud VILLAÇA, 2001, p. 148) compactua com tal visão ao afirmar que:

[...] a distribuição das residências no espaço produz uma diferenciação social e há uma estratificação urbana correspondente a um sistema de estratificação social e, no caso em que a distância social tem uma forte expressão espacial, ocorre a segregação urbana. Segundo ele, 'um primeiro sentido se entenderá por segregação urbana a tendência à organização espacial do espaço em zonas de forte homogeneidade social interna e de forte disparidade social entre elas, entendendo essa disparidade não só em termos de diferença como também em hierarquia'.

Em bairros, onde vivem pessoas de maior nível social, é comum encontrar ruas em ótimo estado de conservação e coleta de lixo eficiente. Ao contrário do que geralmente acontece em bairros mais pobres.

\footnotetext{
${ }^{6}$ SMITH, D. Distribuição dos serviços Municipais. Rio de Janeiro: Saga, 1977.

${ }^{7}$ CASTELLS, M. City, class and power. Londres: The Macmillan Press, 1978.
} 
Harvey (2003) comenta que esse tipo de atração tende a ampliar a renda real daqueles que já possuem elevada renda monetária, ou seja, em contraponto a população mais pobre, além de possuir uma renda inferior, possui um ambiente inferior.

Melgaço et al. (2002), corroboram com Harvey ao afirmarem que a segregação não só é uma das faces mais importantes da exclusão social, mas também um fator desencadeador da desigualdade.

Segundo Crispim (1998), a chegada de turistas e o incremento de capital acabam alterando a dinâmica de um local, pois o espaço começa a ser organizado/reestruturado em função do turismo, surgindo com isso a especulação imobiliária que acaba por segregar a população segundo seu rendimento, porque esta não consegue mais arcar com as altas taxas do preço da terra e dos impostos cobrados nas regiões valorizadas para o turismo.

Outra problemática é quando existe priorização e excessivo investimento em infraestrutura turística, onerando a população e levando-a a arcar com um custo social muito elevado (RODRIGUES, 1996). O Estado poderá aumentar taxas e impostos, a fim de manter a instalação de serviços públicos voltados para a montagem de infraestrutura, como obras de urbanização, paisagismo e serviços de apoio ao turismo, os quais muitas vezes não são disponibilizados para a população local, pois em muitos casos já existe uma nítida segregação espacial que inviabiliza a população de usufruir tais benefícios. ${ }^{8}$ (RODRIGUES, 1996).

Outro fato de grande importância que se refere à urbanização turística é a competição pelo espaço ${ }^{9}$ e pelos serviços urbanos entre turistas e usuários locais. Sobre esse tema, Evans (2001), ao tratar da competição do espaço-patrimônio em conflito entre residentes e turistas do Cairo (Egito), apresenta um modelo de competição por

\footnotetext{
${ }^{8}$ Segundo Rodrigues (1996, p. 157) um exemplo dessa prática pode ser percebido no discurso do Programa de Desenvolvimento do Turismo no Nordeste (PRODETUR-NE), que, teoricamente, teria como objetivo melhorar a infraestrutura da região, para que pudesse assim alavancar investimentos privados, em artesanato, gastronomia e outros. E ainda contribuir para a arrecadação de impostos, para proporcionar benefícios à população local. No entanto, de acordo com a autora, o que se viu na prática foi uma concessão desmedida de benefícios por parte do Estado à iniciativa privada, deixando a população arcar com muitos custos sociais.

${ }^{9}$ Em um estudo realizado por Andereck (1997), intitulado "Territorial functioning tourism setting" (1997), a autora analisa as formas como os turistas defendem seus territórios e os vários conflitos decorrentes deste processo. Segundo ela, a apropriação territorial pode ocorrer de diversas formas (individualmente, em grupo) e intensidades (primário, secundário e público). Reitera ainda que este processo pode ser variar segundo o bojo cultural dos sujeitos que se envolvem neste processo de conquista e defesa do seu território.
} 
esse espaço urbano. Neste estudo de caso, a autora, ilustra ainda os problemas vivenciados pela população pela falta (ou mau funcionamento) de infraestrutura urbana naquela cidade. Existe ainda um modelo exposto por Evans (2001, p. 254) citando como base o trabalho de Burtenshaw et al. (1991) ${ }^{10}$, aplicado em um estudo no Cairo (Egito), que agrega uma importante contribuição para o entendimento do uso do espaço turístico urbano. Observa que tal modelo por sua vez teve como objetivo relacionar as expectativas entre demanda (dos vários atores envolvidos com o processo turístico) e oferta (de objetos espaciais como museus, teatros, restaurantes, cafés, escritórios e outros).

Percebe-se que esse modelo considera as relações e ligações funcionais entre grupos de usuários e recursos disponíveis no local. O modelo no trabalho de Evans (2001, p. 253) apresenta ainda "uma perspectiva espacial, identificando áreas especificas dentro de uma cidade, tais como a cidade histórica, a cidade cultural e a vida noturna do local". As ligações entre usuários e recursos são dadas de dois modos, sendo elas: as ligações primárias, que são as mais importantes e que exprimem prioridade no uso de um determinado recurso, por parte de um grupo de usuários, e as ligações secundárias que apresentam menor grau de importância ou prioridade de um determinado grupo de usuários a um dado recurso.

Essa abordagem permite assim a identificação das prioridades de um determinado grupo de usuários em relação a um recurso. A aplicação sucessiva desse modelo reconhece os padrões de comportamento dos recursos, dos grupos de usuários e de suas intencionalidades. Os recursos podem variar em relação a um tempo histórico e podem ainda apresentar uma variação espacial permitindo desse modo reconhecer a dinâmica espacial dos recursos e a competição por eles. Os grupos de usuários, bem como suas intenções, permitem reconhecer a mudança das demandas sociais em relação aos recursos. Quando as intenções dos usuários em relação a determinados recursos são identificadas, procede-se a uma hierarquização do uso dos recursos, analisando aqueles que são mais ou menos utilizados. Tais informações por sua vez podem subsidiar o processo de planejamento. (EVANS, 2001)

Oliveira (2001), em sua dissertação de mestrado, busca analisar os aspectos das transformações ocorridas no município de Ipanema (SC), nas últimas décadas, em razão

${ }^{10}$ BURTENSHAW et. al. The european city. Londres: David Fulton, 1991. 
do fenômeno turístico e do processo de urbanização e o novo arranjo territorial por ele desencadeado. A autora utiliza as categorias de análise do espaço de Santos (1985) e chega a importantes conclusões não só sobre a alteração das modificações territoriais causadas pelas atividades ligadas ao turismo, mas também sobre as alterações dos fluxos que vêm sufocando o próprio turismo enquanto setor e ocasionando uma segregação socioespacial.

\section{CONCLUSÃO}

Ao analisar alguns casos sobre o desenvolvimento do turismo no meio urbano e a forma como este vem ocorrendo, existe a possibilidade que este, provoque várias transformações, dentre elas a segregação espacial e a competição pelo espaço e por serviços urbanos. Segundo Pearce (2001), o turismo enquanto conjunto de equipamentos, instalações e serviços não se distribui espacialmente de forma equitativa e uniforme, mas se concentra em determinadas áreas, tornando-se assim um obstáculo a ser amenizado, mediante um processo de planejamento turístico. Nessa linha de pensamento, vários autores se remetem ao processo de segregação espacial, onde o turismo pode ser causa ou consequência dessa segregação.

MacCannel (1976 apud PEARCE, 2003, p. 327) ${ }^{11}$ não se utiliza do conceito de segregação espacial, mas utiliza conceitos análogos, tidos como "regiões de frente" e "regiões de fundos", ou "palco" e "bastidores". Segundo esse autor, observa-se que, "frequentemente uma estrutura urbana inteira está operando atrás de sua fachada turística" (PEARCE, 2003, p. 327). Ainda, oferece uma concepção de que o espaço turístico pode ser visto em termos de regiões de frente e de fundos. As regiões de frente, segundo ele, são as que estão prontamente abertas ao visitante, e é também o local de encontro entre hóspedes e convidados. As regiões de fundos "são aquelas restritas aos residentes e trabalhadores, essencialmente orientadas pelo não turismo em sua função" (PEARCE, 2003, p. 327). MacCannel (1999) sugere que há diversas maneiras e graus com os quais os turistas podem adentrar nas regiões dos "bastidores", com o intuito de se inserir em uma verdadeira realidade, ou, ainda, "dar uma olhada no que ocorre "por

${ }^{11}$ MACCANNELL, D. The tourist: A new theory of the leisure class. University of California Press, 1976. 
trás da cena". Ele separa, traz a diferenciação do cenário turístico, onde tudo é preparado para que os visitantes de pontos turísticos observem uma atividade que não lhes é direcionada, isto é, uma visita a uma indústria ou a uma fazenda de modo a observar o trabalho executado pelas máquinas e pelos homens, ou ainda uma autêntica manifestação cultural. Outro cenário, entretanto possui uma cena especialmente ensaiada para o visitante, uma apresentação direcionada exclusivamente para o turismo.

Nesse contexto, inserem-se as representações ou encenações de manifestações culturais desprovidas de autenticidade. (PEARCE, 2003).

Um exemplo que ilustra com propriedade a analogia entre "palco" e "bastidores" é fornecido por Mascarenhas (2004). Ao estudar a forma como o turismo ocorre no interior do Rio de Janeiro, no município de Penedo, devido à valorização do preço da terra, concomitante a um processo de expulsão da população para a periferia, para bairros como África I, África II, Vale do Ermitão e outros comentou que:

\footnotetext{
O mais interessante é a localização destes espaços. Todos encontram-se muito próximos ao eixo turístico de Penedo, mas a topografia permite que mantenham-se "escondidos", preservando assim a paisagem romantizada, da alegria, do consumo, da atmosfera finlandesa. Trata-se de um arranjo altamente segregacionista, que exclui o pobre até mesmo da paisagem tornando-o adequadamente invisível. (MASCARENHAS, 2004, p. 131).
}

Talvez a ideia que melhor explique essa relação da teoria de MacCannell (1999), encontra-se no fato de que o "lugar turístico" tem uma natureza híbrida, como expõe Almeida (1998, p. 125): "espaço vivido e de existência da população local e lugar de representações e imagens para turistas".

Sautter e Leisen (2001), que, ao analisarem os estudos de caso realizados na ilha havaiana de Moloka'i, consideraram que as medidas governamentais foram responsáveis pela segregação da ilha em regiões turísticas e não turísticas. Tal situação corrobora a ideia de Almeida (1998) de um espaço vivido pela população local (não turístico) e um espaço de representações e imagens para turistas.

Melgaco et al. (2002, p. 3) lembram que existe em curso um processo de transformações recentes, que estão gerando espaços nos quais os diferentes grupos sociais estão muitas vezes próximos, mas separados "por muros e tecnologias de segurança, e tendem a não circular ou interagir”. Os autores concebem que tais espaços podem ser entendidos como "enclaves fortificados", que nada mais são do que espaços 
privatizados, fechados e monitorados, que podem ter seu uso residencial, de consumo, lazer ou trabalho.

Dessa forma, a organização e instrumentação do território como um todo devem ser usados como uma forma de se alcançar uma situação social mais igualitária, pois muitas vezes as desigualdades sociais são, em muitos casos, desigualdades territoriais (SANTOS, 2000). Sendo o setor do turismo um dos mecanismos, em muitos casos, responsável pela organização e utilização do espaço, torna-se necessário que este não seja perpetuador de desigualdades e que, ao contrário, procure proporcionar os benefícios de maneira mais equitativa nos territórios ou que ainda crie condições de acessibilidade aos equipamentos e serviços básicos e turísticos de um município.

\section{REFERÊNCIAS}

ALMEIDA, M. G. de. Refletindo sobre o lugar turístico no global. In: CORIOLANO, L. N. M. T. (org.). Turismo com Ética. Fortaleza: UECE, 1998.

ANDERECK, K. L . Territorial functioning in a tourism setting. Annals of Tourism Research. V 24, n 3, 1997, p. 706-720

ASWORTH, G. J.; TUNBRIDGE, J. E. The tourist-historic city: retrospect and prospect of managing the heritage city. Amsterdam: Pergamon, 2000.

BOUllÓN, R. C. Planejamento do Espaço turístico. (tradução de Josely Vianna Baptista). Bauru, São Paulo: Edusc, 2002.

CORRÊA, R. L. Região e organização espacial. 7. ed. São Paulo: Ática, 2000.

CRISPIM, L. de O. O parque temático Beto Carreiro World no contexto do turismo com base local. In: CORIOLANO, L. N. M. T. (org.). Turismo com Ética. Fortaleza: UECE, 1998. p. 390-398

EVANS, K. Competição pelo espaço-patrimônio: o conflito entre residentes e turistas no Cairo. In: TYLER, D.; GUERRIER, Y.; ROBERTSON, M. (orgs.). Gestão do turismo municipal: teoria e prática de planejamento turístico nos centros urbanos. (trad. Gleice Guerra). São Paulo: Futura, 2001. p. 245-262.

FAINSTEIN, S. S.; JUDD, D. R. The tourist city. London : Yale University Press, 1999. 
FERREIRA, L.; AGUIAR, L.; PINTO, J. R. Turismo Cultural, itinerários turísticos e impactos nos destinos. Revista de Cultura e Turismo (CULTUR), ano 6 - n. 2 Jun./2012. Disponível em: <www.uesc.br/revistas/culturaeturismo $>$. Acesso em: $14 / 10 / 2013$.

GARRIDO TORRES, C. Baleares, paraíso perdido. In: JURDAO ARRONES, F. (org.). Los Mitos del turismo. Espanha, Madri: Ediciones Endymion, 1992.

HARVEY, D. Condição pós-moderna: uma pesquisa sobre as origens da mudança cultural. São Paulo, SP: Loyola, 2003.

HALL, M. C. A tomada de decisão política e o planejamento centralizado -Darling Harbour, Sydney. In: TYLER, D.; GUERRIER, Y.; ROBERTSON, M. (orgs.). Gestão do turismo municipal: teoria e prática de planejamento turístico nos centros urbanos. (trad. Gleice Guerra). São Paulo: Futura, 2001. p. 21-40.

JURDAO ARRONES, F. (Org.). Los mitos del turismo. Madrid: Endymion, 1992.

KRIPPENDORF, J. Sociologia do Turismo - Para uma nova compreensão do lazer e das viagens. São Paulo: Aleph, 2000.

LUCHIARI, M. T. D. P. Urbanização turística: um novo nexo entre o lugar e o mundo. In: LUCHIARI, M. T. D. P.; SERRANO, C.; BRUHNS, H. T. (orgs.). Olhares contemporâneos sobre o turismo. Campinas, São Paulo: Papirus, 2000. p. 105-130.

MAcCANNELL, D. The tourist: a new theory of the leisure class. Berkeley: University of Califórnia Press, 1999.

MASCARENHAS, G. Cenários contemporâneos da urbanização turística. Caderno Virtual de Turismo, v. 4, n. 4, 2004, p. 1-11, Universidade Federal do Rio de Janeiro, 2004.

MELGAÇO, Lucas de M. et al. Segregação Sócio-espacial: A materialização espacial da desigualdade. Disponível em:

<http://www.ige.unicamp.br/ lmegaco/trabalhos/segregaçao.PDF>. Acesso em: 08/07/2004.

MINISTÉRIO DO TURISMO DO BRASIL. Dados do Turismo Brasileiro. 2010. Disponível em:

$<$ http://www.turismo.gov.br/export/sites/default/turismo/o_ministerio/publicacoes/down loads_publicacoes/Cartilha-Dados_Turismo-15x21-web.pdf>. Acesso em: 14/10/2013.

NEVEROVSKY, C. Ponta Negra: nova espacialização decorrente do desenvolvimento turístico de Natal, Rio Grande do Norte. In: SEMINÁRIO INTERNACIONAL VISÕES CONTEMPORÂNEAS, 2., 2004, Universidade Federal do Rio de Janeiro, Rio de Janeiro, 2004. Anais em CDROM. 
OLIVEIRA, F. V. de. Capacidade de carga em cidades históricas. Campinas. São Paulo: Papirus, 2003.

OLIVEIRA, S. D. Análises espaciais como apoio à gestão turística da Ilha de Santa Catarina. Florianópolis/SC, 2001. 120 p. Dissertação (Mestrado em Engenharia da Produção) - Programa de Pós-graduação em Engenharia de produção, Universidade Federal de Santa Catarina.

ORBASLI, A. Tourists in historic tows: urban conservation and heritage management. London: E \& FN Spon, 2000.

PEARCE, D. Dessarrollo turístico: su planificación y ublicación geográficas. México: Trilhas, 1985.

PEARCE, D. Tourism in Paris: Studies at the Microscale. Annals of Tourism Research, V 26, n. 1, p. 77- 97, 1999 Aleph, 2003.

Geografia do Turismo: fluxos e regiões no mercado de viagens. São Paulo:

Un Esquema Integrador para la investigacion del turismo urbano. Annals of Tourism Research en Espanhol. Universitat de les IIIes Balears. V 3, n. 2, p. 340-363, 2001.

REBOLLO, F. V. Turismo y Crisis Agraria en el Litoral Alicantino. In: JURDAO ARRONES, F. (org.). Los Mitos del turismo. Espanha, Madri: Ediciones Endymion, 1992.

RODRIGUES, A. B. Percalços do Planejamento Turístico: o Prodetur -NE. In: RODRIGUES, A. B. (Org.). Turismo e geografia: reflexões teóricas e enfoques regionais. São Paulo: Hucitec, 1996, p. 145-162.

São Paulo: Hucitec, 1999.

Turismo e espaço: rumo a um conhecimento transdisciplinar. 2. ed.

SAUTTER, E. T.; LEISEN, B. La gestion de las partes interessadas: un modelo de planificación turística. Annals of Tourism Research en Espanhol. Universitat de les IIIes Balears. v. 3, n. 1, p. 101-119, 2001.

SANTOS, M. Espaço e método. São Paulo: Nobel, 1985.

SANTOS, M. A natureza do espaço - Técnica e tempo. Razão e emoção. São Paulo: Hucitec, 1996.

SANTOS, M. O espaço do cidadão. São Paulo: Nobel, 2000.

SILVA, M. da G. L. Cidades Turísticas: Identidades e Cenários de Lazer. São Paulo: Aleph, 2004. 
SILVEIRA, M. A. T. da. Turismo e espaço urbano: uma abordagem de Curitiba. In: Da cidade ao campo: a diversidade do saber-fazer turístico. In: LIMA, L. C. de. (org.). Fortaleza: UECE, 1998. p. 60-81.

TYLER, D.; GUERRIER Y. Conclusão: Turismo Urbano - a Política e o processo de mudança. In: TYLER, D.; GUERRIER, Y.; ROBERTSON, M. (orgs.). Gestão do turismo municipal: teoria e prática de planejamento turístico nos centros urbanos. (trad. Gleice Guerra). São Paulo: Futura, 2001 p. 309-319.

URRY, J. O Olhar do Turista: lazer e viagens nas sociedades contemporâneas. $3^{\text {a }}$ ed. São Paulo: Studio Nobel, Sesc, 2001.

VILLAÇA, F. Espaço Intra-urbano no Brasil. São Paulo: Studio Nobel: FAPESP: Lincoln Institute, 2001.

YÁZIGI, E. Civilização urbana, planejamento e turismo: discípulos do amanhecer. São Paulo: Contexto, 2003.

Recebido em: 31-08-2013.

Aprovado em: 30-09-2013. 